\title{
Food Prices
}

Retail food prices in 1997, as measured by the Consumer Price Index (CPI), averaged 2.6 percent above those in 1996 (table 94). This 1997 increase was slower than 1996's rise of 3.3 percent. Food price inflation in 1997 was higher than the overall increase in the CPI (2.3 percent) for the third consecutive year (fig. 27).

Food prices in 1997 rose slightly more at eating places than at supermarkets and other grocery stores (fig. 28, table 95). Food prices in grocery stores rose 2.5 percent, while prices for restaurant meals advanced at the slightly faster pace of 2.8 percent. Grocery store prices of foods advanced at a slower pace in 1997 than in 1996. The food groups whose retail prices increased the most in 1997 were coffee, lettuce, tomatoes, and pork (table 96). Prices of cereal and cereal products, fresh fruits, and fats and oils increased less than 1 percent, while prices of eggs, apples, oranges, potatoes, and carbonated drinks declined. The food at home index was held in check by low grain prices, large supplies of competing meats (especially pork and poultry), and large supplies of fresh produce. Higher marketing costs were a major factor that raised food prices, as is the case in most years.
Prices of restaurant meals increased slightly more in 1997 than they did the year before, consistent with the pattern of relatively small restaurant price increases during the 1990's. These small price hikes were largely due to increased competition among restaurants, which held down menu price increases. However, the 1997 increase was the largest since 1991's 3.4-percent hike. This rise reflected a tight labor market that featured low unemployment rates due to the strong economy. A Federally mandated minimum wage increase further augmented 1997 restaurant operating costs and, therefore, prices paid by consumers.

Food prices in 1997 rose more than prices for most other consumer products and services (table 94). Among major items in the CPI, housing prices, the largest component, went up 2.6 percent, while transportation and apparel both rose 0.9 percent. The largest increase was again in medical costs, which climbed 2.8 percent - the smallest increase since 1965. 